\title{
(6) OPEN ACCESS \\ Prognostic value of bone marrow involvement by clonal immunoglobulin gene rearrangements in follicular lymphoma
}

\author{
Ellen Berget, ${ }^{1,2}$ Lars Helgeland, ${ }^{1,2}$ Knut Liseth, ${ }^{3}$ Turid Løkeland, ${ }^{4}$ Anders Molven, ${ }^{1,2}$ \\ Olav Karsten Vintermyr ${ }^{1,2}$
}

- Additional material is available. To view please visit the journal online (http://dx. doi.org/10.1136/jclinpath2014-202382).

${ }^{1}$ The Gade Laboratory for Pathology, Department of Clinical Medicine, University of Bergen, Bergen, Norway ${ }^{2}$ Department of Pathology, Haukeland University Hospital, Bergen, Norway ${ }^{3}$ Department of Immunology and Transfusion Medicine, Haukeland University Hospital, Bergen, Norway

${ }^{4}$ Department of Oncology, Haukeland University Hospital, Bergen, Norway

Correspondence to Professor Olav Karsten Vintermyr, Department of Pathology, Haukeland University Hospital, Bergen N-5021, Norway; olav. vintermyr@helse-bergen.no

Received 25 April 2014 Revised 25 July 2014 Accepted 26 August 2014 Published Online First 18 September 2014

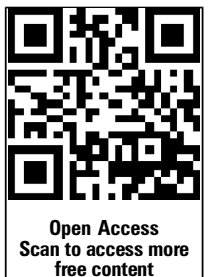

CrossMark

To cite: Berget $\mathrm{E}$, Helgeland L, Liseth $\mathrm{K}$, et al. J Clin Pathol

2014;67:1072-1077.

\section{ABSTRACT}

Aims We aimed to evaluate the prognostic value of routine use of PCR amplification of immunoglobulin gene rearrangements in bone marrow (BM) staging in patients with follicular lymphoma (FL).

Methods Clonal rearrangements were assessed by immunoglobulin heavy and light-chain gene rearrangement analysis in BM aspirates from 96 patients diagnosed with $\mathrm{FL}$ and related to morphological detection of BM involvement in biopsies. In 71 patients, results were also compared with concurrent flow cytometry analysis.

Results BM involvement was detected by PCR in $34.4 \%$ (33/96) of patients. The presence of clonal rearrangements by PCR was associated with advanced clinical stage (I-III vs IV; $p<0.001$ ), high FL International Prognostic Index (FLIPI) score (0-1, 2 vs $\geq 3 ; p=0.003$ ), and detection of $\mathrm{BM}$ involvement by morphology and flow cytometry analysis ( $p<0.001$ for both). PCR-positive patients had a significantly poorer survival than PCRnegative patients ( $p=0.001$, log-rank test). Thirteen patients positive by PCR but without morphologically detectable BM involvement, had significantly poorer survival than patients with negative morphology and negative $P C R$ result $(p=0.002)$. The poor survival associated with BM involvement by PCR was independent of the FLIPI score $(p=0.007$, Cox regression). BM involvement by morphology or flow cytometry did not show a significant impact on survival. Conclusions Our results showed that routine use of PCR-based clonality analysis significantly improved the prognostic impact of BM staging in patients with $\mathrm{FL}$. BM involvement by PCR was also an independent adverse prognostic factor.

\section{INTRODUCTION}

Bone marrow (BM) examination is routinely performed in the staging of B-cell lymphoma. The presence of $\mathrm{BM}$ involvement results in a clinical stage IV classification, is associated with less favourable prognosis, and may influence treatment decisions. ${ }^{1-6}$ The $\mathrm{BM}$ is involved in $40 \%-70 \%$ of follicular lymphoma (FL) cases. $^{7} 8$

Diagnosis of BM involvement has traditionally been based on morphological findings, but the evaluation by morphological features has limitations. BM involvement is frequently patchy, and it is not always possible to obtain optimal biopsies in routine practice. In addition to low sensitivity, it is often difficult to distinguish benign lymphoid aggregates composed of small lymphoid cells from infiltrates of malignant lymphoma. $^{9-11}$ This problem is especially common in BM biopsies acquired from elderly patients, the age group with the highest incidence of both benign lymphoid aggregates and B-cell lymphomas. ${ }^{12} 13$

The BIOMED-2 multitarget PCR approach has improved clonality testing and is increasingly used in the diagnostics of B-cell malignancies. The highest detection rates $(>98 \%)$ are reached with the combined use of immunoglobulin heavy $(I G H)$ and $\mathrm{k}$ light (IGK) chains analyses. ${ }^{14-16}$ However, there have been few reports evaluating the use of BIOMED-2 primers in BM staging and only one of these reports included IGK analysis. ${ }^{17-19}$ Furthermore, there have been only occasional studies attempting to correlate PCR results with clinical outcome, ${ }^{18-21}$ and none of these focused on FL.

In the present study, we have therefore evaluated the contribution and prognostic value of PCR-based clonality in BM staging of FL using BIOMED-2 primers.

\section{MATERIALS AND METHODS \\ Patient selection}

All patients with FL $(n=96)$ who had a BM aspirate and a BM biopsy obtained at diagnosis in the period between March 2003 and July 2011 at Haukeland University Hospital, Bergen, were included in the study. Diagnoses of FL (grades 1-3B) were based on morphological and immunohistochemical assessment of formalin-fixed, paraffin-embedded (FFPE) tumour biopsies from lymph nodes and extranodal sites, and were classified in accordance with the 2008 WHO classification of lymphoid malignancies. ${ }^{22}$ Clinical information including treatment and survival data was collected from medical records. Clinical stage, according to the Ann Arbor system, was determined on findings from computed tomographic scans of the neck, thorax, abdomen and pelvis as well as the BM biopsy. Patients were assigned to specific risk groups according to the FL International Prognostic Index (FLIPI). ${ }^{2}$ The study was approved by the Regional Committee for Medical and Health Research Ethics (2013/211) and performed in accordance with the Declaration of Helsinki.

\section{BM morphology}

BM biopsies were fixed in $4 \%$ formalin, decalcified overnight in EDTA $(75 \mathrm{mg} / \mathrm{mL})$, embedded in paraffin, sectioned and stained with H\&E. The mean biopsy length was $14.5 \mathrm{~mm}$ with a range of $5-31 \mathrm{~mm}$. Routine immunohistochemical stains included CD20, CD3, $\kappa$ and $\lambda$ immunoglobulin light chain stains, and were performed on a Dako 
Autostainer (Dako, Glostrup, Denmark). All BM biopsies were examined by experienced haematopathologists in routine practice and the original reports of BM morphology were used.

\section{PCR-based clonality}

DNA was extracted from BM aspirates and from FFPE tissue of the initial tumours in patients with a clonal result obtained in the BM $(n=33)$. The fresh aspirates were collected in EDTA $(1.8 \mathrm{mg} /$ $\mathrm{mL}$ ) and lymphocytes were isolated using Fiqoll-Paque PLUS medium (GE Healthcare, Little Chalfont, Buckinghamshire, UK). From FFPE tissue, two $10 \mu \mathrm{m}$ sections were deparaffinised with xylene and dehydrated in alcohol. Isolated lymphocytes and deparaffinised tissue were digested overnight with proteinase $\mathrm{K}$ $(20 \mathrm{mg} / \mathrm{mL})$. DNA was prepared manually using the EZNA Tissue DNA kit according to the manufacturer's instructions (Omega Bio-Tek, Norcross, Georgia, USA).

PCR analyses were performed using BIOMED-2 primers as previously described. ${ }^{14} 23$ The $\mathrm{VH}_{\mathrm{H}} \mathrm{FR} 3-\mathrm{JH}$ primers were used in

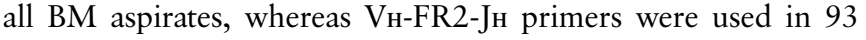
and the $\mathrm{V} \kappa-\mathrm{J} \kappa$ primers in 94 owing to limited amounts of DNA. In nine aspirates, in which the three primer sets were negative and $\mathrm{BM}$ morphology was positive, analysis with the $\mathrm{V}_{\mathrm{H}}-\mathrm{FR} 1-\mathrm{JH}_{\mathrm{H}}$ and $\mathrm{V}_{\mathrm{K}}$ /intron-Kde primers was added. The choice of primers was based on our previous analyses on FFPE FL samples showing detection rates of $91.5 \%$ and $94.9 \%$ for the threeprimer and five-primer combinations, respectively. ${ }^{23}$ PCR products were subjected to fragment analysis on an ABI 3100 capillary sequencer (Applied Biosystems, Foster City, California, USA). Clonality was determined by the presence of one or two distinct peaks within the expected size range.

\section{Flow cytometry}

Reports on concurrent immunophenotyping of BM aspirates were retrieved from laboratory records of 71 patients. Eleven analyses were performed on a four-colour Coulter Epics XL flow cytometer (Beckman Coulter, Brea, California, USA) and 60 analyses on an eight-colour FACSCanto II flow cytometer (Becton Dickinson, Franklin Lakes, New Jersey, USA). Flow cytometric two-parameter dot plots and quadrant statistics were generated by Cellquest software (Becton-Dickinson Immunocytometry Systems). All 71 samples were tested for expression of CD5, CD10, CD11c, CD19, CD20, CD22, CD23, CD45 and $\kappa$ and $\lambda$ light chains. For most samples, clonality was defined as light chain restriction with a $\kappa: \lambda$ ratio of $>3: 1$ or $<0.3: 1$. These cut-off values were not used, or used with great care, in patients with low amounts of CD19+/CD20+/CD45+ cells. Clonal samples or samples evaluated as being suspect for clonality were tested for the expressiom of the additional markers CD25, CD31, CD38, CD43, CD79b, CD81, CD103, CD200, HLA-DR and LAIR1.

\section{Statistical analysis}

The Pearson's $\chi^{2}$ and Fisher's exact tests were performed to compare categorical variables. Survival curves of time to death due to lymphoma were estimated using the product-limit procedure (Kaplan-Meier method) with date of histological diagnosis as starting point. Differences between categories were estimated by log-rank statistics. Patients who died of other causes than lymphoma were treated as censored observations. Median follow-up time was estimated by the reversed KaplanMeier method. Univariate and multivariate analyses were performed with the Cox proportional hazards method. The variables were tested by a log-log plot, and the proportionally assumption did not seem to be violated. Backward and forward selections of variables were performed to determine the variables ability to be incorporated in multivariate models. All results were considered significant if $\mathrm{p} \leq 0.05$. SPSS V.21.0 (SPSS, Chicago, Illinois, USA) was used for all statistical analyses.

\section{RESULTS}

\section{Clinical characteristics}

The patients' ages ranged from 33 to 82 years (median 61 years). Treatment data were available for all patients. Fifty-eight patients were initially treated with cyclophosphamide, hydroxydaunorubicin, oncovin and prednisolone (CHOP) or COP. Rituximab was added in 55 and radiation therapy was applied as consolidation in 17 of these patients. Nine patients received chlorambucil. Fifteen patients with stage I or II and grade 1 or 2 FLs were treated with local radiation therapy. Fourteen patients were observed. Median follow-up time for the patients was 61 months.

\section{BM involvement by morphology and PCR-based clonality}

BM involvement was reported in 30.2\% (29/96) of BM biopsies. Characteristic CD20-positive paratrabecular infiltrates were described in all these biopsies.

BM involvement was detected by PCR-based clonality in $34.4 \%$ (33/96) of BM aspirates. FFPE tissue from the primary tumour showed identically sized clonal rearrangement in 31 of these cases. In two cases, the PCR product from the primary tumour consisted of few amplified fragments of small size $(<250 \mathrm{bp})$ and was considered insufficient for the detection of clonality.

Thirteen cases without morphologically detectable BM involvement were positive by PCR. Representative images of $\mathrm{BM}$ biopsies in two cases that were negative by morphology and in which PCR was positive or negative, are shown in figure 1.

Frequencies of PCR-positive aspirates in relation to FL grade, BM involvement by morphology and clinical variables studied for all 96 patients are shown in table 1. The presence of PCR-based clonality in aspirates was associated with morphological detection of BM involvement $(\mathrm{p}<0.001)$, clinical stage IV $(\mathrm{p}<0.001)$ and FLIPI score $\geq 3(\mathrm{p}=0.003)$.

\section{BM involvement by flow cytometry}

BM involvement by flow cytometry was reported in $23.9 \%$ (17/71) of patients (table 2). There was a significant association between BM involvement detected by flow cytometry and by morphology $(p=0.004)$ or by PCR $(p<0.001)$.

\section{Prognostic significance of BM involvement}

The estimated survival at 60 months for patients with and without BM involvement by PCR was $81.3 \%$ (SE 6.9\%) and 97.7\% (SE 2.3\%). PCR-positive patients had a significantly poorer survival than PCR-negative $(p=0.001$, figure 2A), whereas, involvement by morphology showed no significant impact on survival $(p=0.742$, figure $2 B)$. The HR for BM involvement by PCR was estimated at 8.23 (95\% CI 1.77 to $38.32)$ and at 5.42 (95\% CI 1.16 to 25.31 ) when used in addition to morphology (table 3 ).

The estimated survival at 60 months for patients with negative BM morphology and negative PCR was 97.3\% (SE 2.7\%), for patients with positive BM morphology 88.5\% (SE 6.3\%) and for patients with negative BM morphology and positive PCR 76.9\% (SE 11.7\%). The last group of patients had a significantly poorer survival than the first $(p=0.002$, figure $2 \mathrm{C})$. The same results were obtained, when survival analysis was performed after exclusion of the two patients with BM involvement by PCR and in whom diagnostic tumour biopsies were not evaluable by PCR-based clonality analysis. 

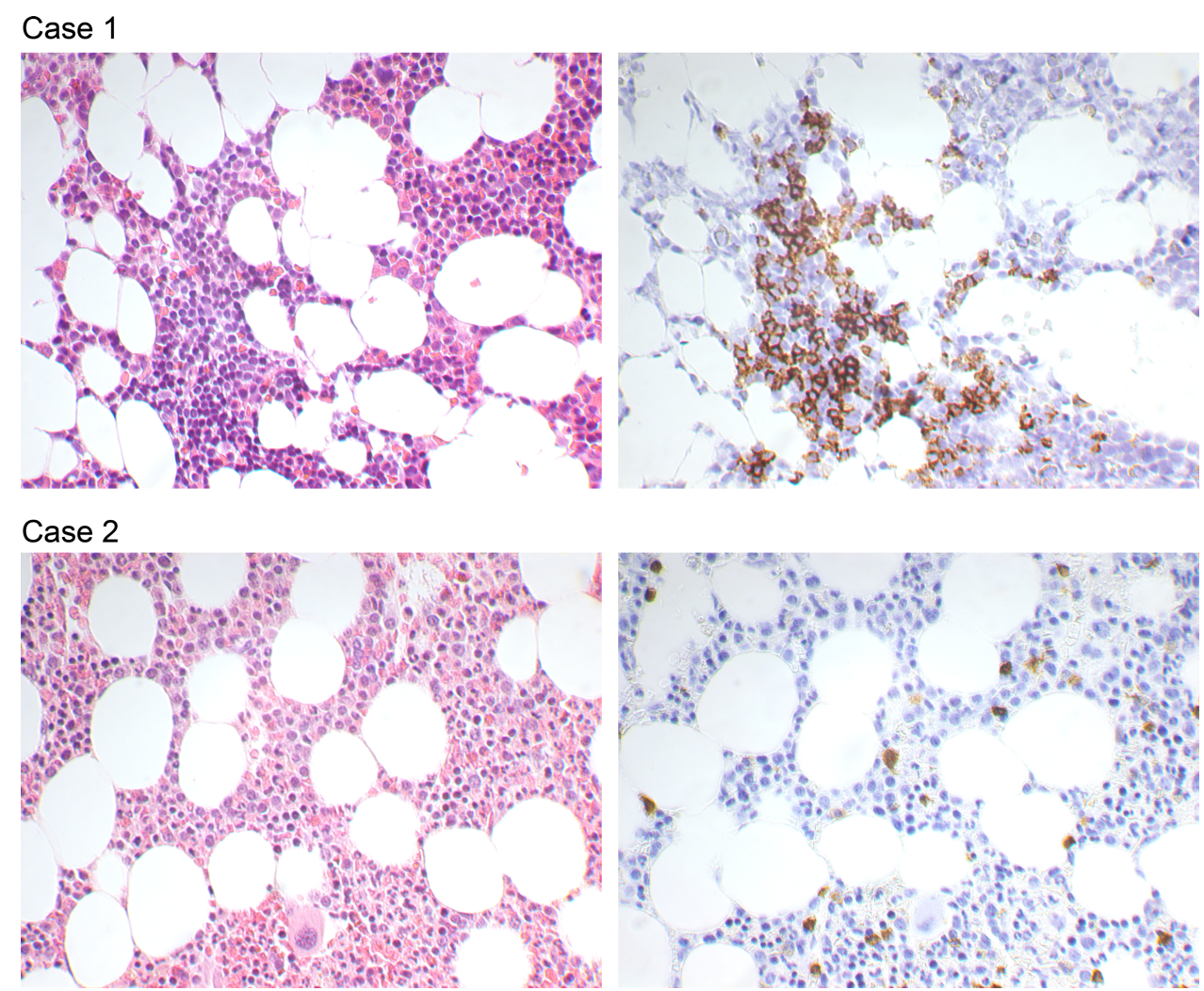

Figure 1 Images from two follicular lymphoma cases, where bone marrow (BM) biopsies were reported negative for morphological BM involvement. PCR was negative in the case of the upper panel and positive in the case of the lower panel. The images show H\&E stained sections (left) and immunohistochemistry by CD20 (right). Magnification $\times 400$.

Seventy-one patients had performed concurrent flow cytometric immunophenotyping. BM involvement by flow cytometry did not show statistically significant impact on survival neither when used alone nor in addition to morphology $(\mathrm{p}=0.143$ and $\mathrm{p}=0.160$, respectively, table 4$)$.

\section{FLIPI score and multivariate analysis}

Significantly poorer survival was observed in patients with high FLIPI score $(\geq 3)$ as compared with patients with low or intermediate FLIPI scores $(p=0.017$, table 3$)$. Presence of BM involvement by PCR was an independent prognostic factor by multivariate analysis (HR 9.34, 95\% CI 1.85 to 47.30, $\mathrm{p}=0.007)$ when high FLIPI score $(\geq 3)$ was incorporated (table 5). When PCR was used as a prognostic factor in addition to BM morphology, the HR was 4.79 (95\% CI 0.99 to 23.07, $\mathrm{p}=0.051)$ in the multivariate model (data not shown).

\section{DISCUSSION}

We have evaluated the performance of routine use of PCR-based immunoglobulin rearrangement analysis in the diagnosis of BM involvement in FL.

A variety of approaches have been used for the detection of B-cell clonality in BM staging, ${ }^{17} 182021{ }^{24-30}$ and most previous studies have used consensus primers against framework region 3 or framework region 2 of the IGH gene. $^{20}{ }^{24-30}$ Using BIOMED-2 primers, we detected BM involvement by PCR-based clonality in 13 patients without morphologically detectable BM involvement. To our knowledge, this is the first study evaluating the prognostic value of PCR-based clonality in BM staging of patients with FL. PCR-positive cases had a significantly poorer survival than PCR-negative, and the presence of
BM involvement by PCR was also an independent prognostic factor by multivariate analysis. Furthermore, patients with positive PCR but without morphologically detectable BM involvement had a significantly poorer survival than patients who were negative by both PCR and morphology.

By contrast, BM involvement by morphology was not a significant predictor of poor survival in our study. There are conflicting reports regarding the prognostic impact of $\mathrm{BM}$ involvement in patients with FL. BM involvement by morphology has been associated with decreased survival in several investigations including those of the FLIPI studies. ${ }^{2} 5$ Others have found the morphological pattern or degree of involvement rather than BM involvement by itself to affect survival. ${ }^{8} 3132 \mathrm{In}$ our study, the evaluation of involvement by morphology was based on the original pathology reports, and morphological BM involvement $(30.2 \%)$ was somewhat lower than previously reported for FL cases. ${ }^{7}$ We, therefore, reviewed the BM biopsies of all PCR-positive cases with negative pathology reports. Of the 13 cases, five showed no lymphoid aggregates, whereas, eight showed one or two small lymphoid aggregates. These were predominantly composed of small CD20-positive cells and only in two cases a paratrabecular localisation could be seen. Thus, the relatively low fraction of BM involvement by morphology could not, in general, be explained by wrong classification in the original reports. The insignificant prognostic impact of BM involvement by morphology in our study may reflect that minimal changes not always can be detected by conventional methods, as also observed by others. ${ }^{9-11} 33$

We also performed a histology review of the nine cases that had positive $\mathrm{BM}$ involvement by morphology, but were negative by PCR in the aspirates. Four biopsies showed one or two small 
Table 1 Clinicopathological factors according to the detection of BM involvement by PCR-based clonality in 96 cases of follicular lymphoma

\begin{tabular}{|c|c|c|c|c|c|}
\hline \multirow[b]{2}{*}{ Variables } & \multirow[b]{2}{*}{$\mathrm{n}$} & \multicolumn{2}{|c|}{ PCR-based clonality } & \multirow[b]{2}{*}{ p Value* } & \\
\hline & & $\begin{array}{l}\text { No involvement } \\
(\%)\end{array}$ & $\begin{array}{l}\text { Involvement } \\
(\%)\end{array}$ & & \\
\hline \multicolumn{6}{|l|}{ Sex } \\
\hline Female & 59 & $36(61.0)$ & $23(39.0)$ & & \\
\hline Male & 37 & $27(73.0)$ & $10(27.0)$ & 0.230 & \\
\hline \multicolumn{6}{|l|}{ Age (years) } \\
\hline$\leq 60$ & 42 & $30(71.4)$ & $12(28.6)$ & & \\
\hline$>60$ & 54 & $33(61.1)$ & $21(38.9)$ & 0.291 & \\
\hline \multicolumn{6}{|l|}{ WHO grade } \\
\hline 1 & 35 & $20(57.1)$ & $15(42.9)$ & & \\
\hline 2 & 30 & $21(70.0)$ & $9(30.0)$ & & \\
\hline $3 A$ and $3 B$ & 31 & $22(71.0)$ & $9(29.0)$ & 0.447 & $(1,2$ vs 3$)$ \\
\hline \multicolumn{6}{|l|}{ BM morphology } \\
\hline No involvement & 67 & $54(80.6)$ & $13(19.4)$ & & \\
\hline Involvement & 29 & $9(31.0)$ & $20(69.0)$ & $<0.001$ & \\
\hline \multicolumn{6}{|l|}{ Clinical stage } \\
\hline 1 & 16 & $14(87.5)$ & $2(12.5)$ & & \\
\hline ॥ & 16 & $16(100.0)$ & $0(0.0)$ & & \\
\hline III & 34 & $24(70.6)$ & $10(29.4)$ & & \\
\hline IV & 30 & $9(30.0)$ & $21(70.0)$ & $<0.001$ & (I-III vs IV) \\
\hline \multicolumn{6}{|l|}{ FLIPI score } \\
\hline Low (0-1) & 45 & $37(82.2)$ & $8(17.8)$ & & \\
\hline Intermediate (2) & 23 & $14(60.9)$ & $9(39.1)$ & & \\
\hline High $(\geq 3)$ & 28 & $12(42.9)$ & $16(57.1)$ & 0.003 & $(0-2$ vs $\geq 3)$ \\
\hline
\end{tabular}

paratrabecular lymphoid aggregates, three exhibited several paratrabecular lymphoid aggregates and two had densely packed marrows with tumour cells. Possible explanations for the negative PCR results in these cases may be related to the frequency of somatic hypermutations in FL that hamper binding efficiency of primers. Furthermore, a clonal rearrangement, identically sized to that of the primary tumour, was achieved in the corresponding BM biopsy in one of these cases, suggesting that false negative PCR results also might be related to the inadequacy of sampled aspirates.

Table 2 Comparison of bone marrow (BM) involvement by flow cytometry, morphology and PCR-based clonality in the 71 cases with results from immunophenotyping of aspirates

\begin{tabular}{|c|c|c|c|c|}
\hline \multirow[b]{2}{*}{ BM involvement } & \multirow[b]{2}{*}{ N } & \multicolumn{2}{|c|}{ Flow cytometry analysis } & \multirow[b]{2}{*}{$P$ value* } \\
\hline & & No involvement (\%) & Involvement (\%) & \\
\hline \multicolumn{5}{|l|}{ Morphology } \\
\hline No involvement & 49 & $42(85.7)$ & $7(14.3)$ & \\
\hline Involvement & 22 & $12(54.5)$ & $10(45.5)$ & 0.004 \\
\hline \multicolumn{5}{|l|}{ PCR } \\
\hline No involvement & 45 & $43(95.6)$ & $2(4.4)$ & \\
\hline Involvement & 26 & $11(42.3)$ & $15(57.7)$ & $<0.001$ \\
\hline \multicolumn{5}{|c|}{ Morphology and/or PCR } \\
\hline No involvement & 39 & $38(97.4)$ & $1(2.6)$ & \\
\hline Involvement & 32 & $16(50.0)$ & $16(50.0)$ & $<0.001$ \\
\hline
\end{tabular}
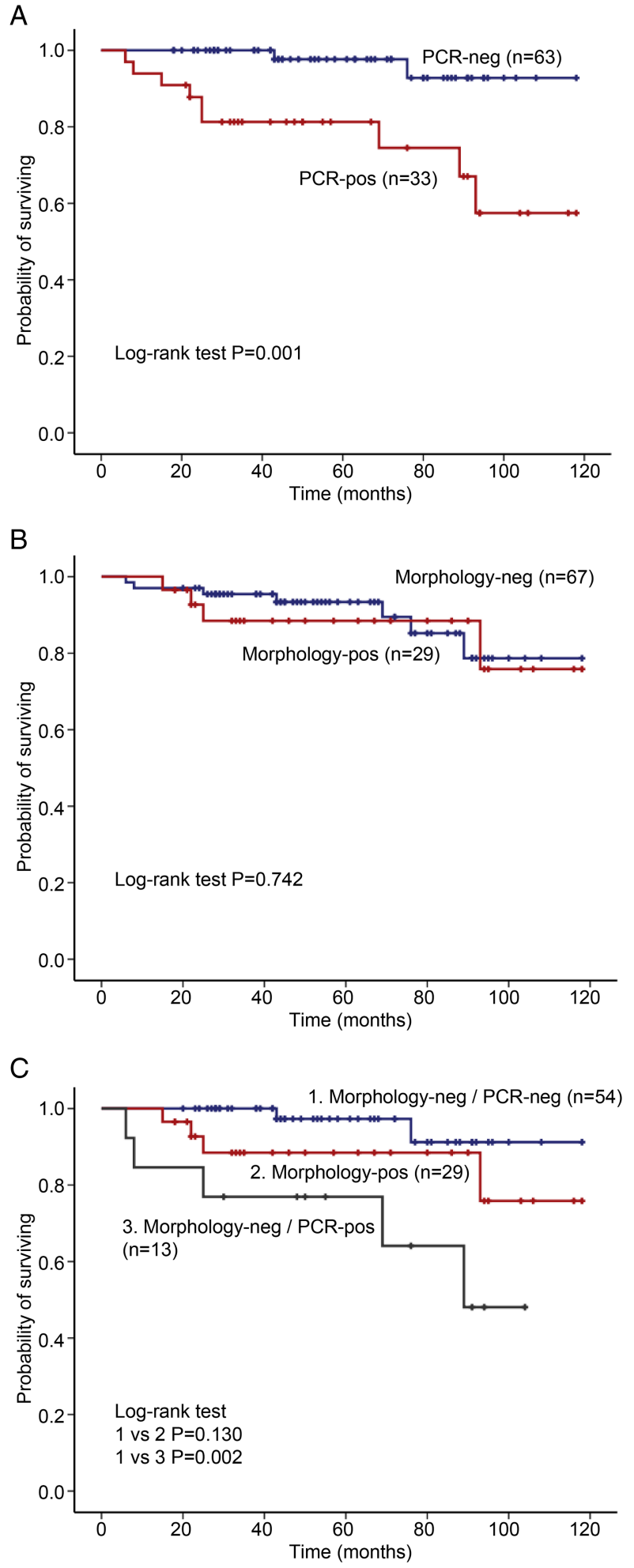

Figure 2 Kaplan-Meier survival curves of patients with follicular lymphoma according to the presence of bone marrow (BM) involvement by PCR-based clonality (A) and by morphology (B). (C), Survival curves of $B M$ involvement by morphology, and to the presence of PCR-based clonality without morphologically detectable BM involvement. Statistical differences were calculated by the log-rank test. Neg, negative; pos, positive.

Notably, PCR-based BM involvement showed a strong prognostic impact, even when this analysis in some cases did not detect definite BM involvement as judged by morphology. This 
Table 3 Survival studies by univariate Cox's regression analysis in 96 cases of follicular lymphoma

\begin{tabular}{|c|c|c|c|c|}
\hline Variables & $\mathbf{n}$ & HR & $95 \% \mathrm{Cl}$ & p Value* \\
\hline \multicolumn{5}{|l|}{ Sex } \\
\hline Female & 59 & 1 & & \\
\hline Male & 37 & 1.923 & 0.568 to 6.536 & 0.285 \\
\hline \multicolumn{5}{|l|}{ Age (years) } \\
\hline$\leq 60$ & 42 & 1 & & \\
\hline$>60$ & 54 & 3.316 & 0.715 to 15.387 & 0.104 \\
\hline \multicolumn{5}{|l|}{ WHO grade } \\
\hline Grades 1 and 2 & 65 & 1 & & \\
\hline Grade $3 \mathrm{~A}$ and $3 \mathrm{~B}$ & 31 & 1.050 & 0.566 to 1.951 & 0.876 \\
\hline \multicolumn{5}{|l|}{ BM morphology } \\
\hline No involvement & 67 & 1 & & \\
\hline Involvement & 29 & 1.232 & 0.356 to 4.262 & 0.742 \\
\hline \multicolumn{5}{|l|}{ Clinical stage } \\
\hline$|-| I \mid$ & 66 & 1 & & \\
\hline IV & 30 & 1.070 & 0.786 to 1.457 & 0.667 \\
\hline \multicolumn{5}{|l|}{ FLIPI score } \\
\hline Low and intermediate $(0-1,2)$ & 68 & 1 & & \\
\hline $\operatorname{High}(\geq 3)$ & 28 & 3.994 & 1.164 to 13.700 & 0.017 \\
\hline \multicolumn{5}{|l|}{ BM by PCR } \\
\hline No involvement & 63 & 1 & & \\
\hline Involvement & 33 & 8.232 & 1.768 to 38.322 & 0.001 \\
\hline \multicolumn{5}{|l|}{ BM by morphology and/or PCR } \\
\hline No involvement & 54 & 1 & & \\
\hline Involvement & 42 & 5.423 & 1.162 to 25.313 & 0.016 \\
\hline
\end{tabular}

would indicate that PCR detects an additional group of patients with BM involvement and severe prognosis. We have considered the possibility that the PCR-positive, morphology-negative patients could have received different therapy than the other groups, but did not observe any obvious treatment differences when reviewing their medical records. Another explanation could be that PCR might have detected blood involvement instead of BM involvement. A review of the medical records showed that none of the 13 morphology-negative, PCR-positive patients had detectable leukaemic phase by standard blood tests. However, this does not exclude that PCR, at least in some cases, did detect circulating lymphoma cells, which could have contributed to the observed adverse prognosis.

Table 4 Survival studies by univariate Cox's regression analysis according to bone marrow (BM) involvement in the 71 patients with results from immunophenotyping of aspirates

\begin{tabular}{lllll}
\hline BM involvement & N & HR & $95 \%$ Cl & p Value* \\
\hline Flow cytometry analysis & & & & \\
No involvement & 54 & 1 & & \\
Involvement & 17 & 2.581 & 0.690 to 9.661 & 0.143 \\
Morphology and/or flow cytometry analysis & & \\
No involvement & 42 & 1 & & \\
Involvement & 29 & 2.683 & 0.639 to 11.274 & 0.160 \\
Morphology and/or flow cytometry analysis and/or PCR & \\
No involvement & 38 & 1 & & 0.016 \\
Involvement & 33 & 8.519 & 1.043 to 69.605 & \\
\hline
\end{tabular}

Table 5 Multivariate Cox's regression analysis of prognostic factors in 96 cases of follicular lymphoma

\begin{tabular}{llll}
\hline Variables & HR & 95\% Cl & p Value \\
\hline Male sex & 3.279 & 0.803 to 13.333 & 0.098 \\
Age $>60$ years & 2.749 & 0.578 to 13.064 & 0.203 \\
FLIPI score $\geq 3$ & 1.971 & 0.528 to 7.352 & 0.313 \\
BM involvement by PCR & 9.342 & 1.845 to 47.304 & 0.007 \\
\hline
\end{tabular}

BM, bone marrow; FLIPI, Follicular Lymphoma International Prognostic Index.

Seventy-one of our patients with FL had performed concurrent flow cytometry, which turned out to be the least sensitive method for detection of BM involvement. There was no significant difference in survival using flow cytometry analysis alone or in addition to morphology. Our results were in accordance with several previous studies showing that flow cytometry analysis underestimates the extent of BM involvement with respect to morphology in BM staging of FL, possibly because of the predominantly paratrabecular infiltration typical for FL cases. ${ }^{34-39}$ However, the discrepant results with respect to PCR cannot easily be explained by the method of sampling. Further development of multicolour flow cytometry may lead to increased sensitivity of this technique.

In conclusion, although validation in larger series is warranted, our data suggest an important contribution of PCR-based clonality analysis in BM staging of patients with FL. The prognostic value of BM staging was improved by performing PCR analysis, and BM involvement by PCR was also an adverse prognostic factor independent of high FLIPI score. It should be emphasised that our results do not indicate that PCR-based clonality analysis of BM aspirates can replace morphological examination of BM biopsies, but rather support the inclusion of PCR in routine BM staging of FL.

\section{Take home messages}

- The prognostic value of bone marrow staging in follicular lymphoma was improved by PCR-based clonality analyses.

- Bone marrow involvement by PCR predicts a poor clinical outcome independent of high FL International Prognostic Index score.

Acknowledgements The authors would like to acknowledge Dr Roald Ekanger for contributing to this work. This study was funded by a grant provided by the Western Norway Regional Health Authority. There are no conflicts of interest to declare.

Contributors All authors contributed substantially in the conception and design of the study. EB performed practical work, statistical analyses and data interpretation, and drafted the manuscript. $\mathrm{LH}, \mathrm{KL}, \mathrm{TL}$ and $\mathrm{AM}$ participated in the acquisition and interpretation of data, and revised the manuscript critically. OKV conceived and designed the study, and contributed in data interpretation and in writing of the manuscript. All authors have read and approved the final manuscript.

Funding The Western Norway Regional Health Authority.

Competing interests None.

Ethics approval Regional Committee for Medical and Health Research Ethics. Provenance and peer review Not commissioned; externally peer reviewed.

Open Access This is an Open Access article distributed in accordance with the Creative Commons Attribution Non Commercial (CC BY-NC 4.0) license, which permits others to distribute, remix, adapt, build upon this work non-commercially, and license their derivative works on different terms, provided the original work is properly cited and the use is non-commercial. See: http://creativecommons.org/ licenses/by-nc/4.0/ 


\section{REFERENCES}

1 Shipp MA, Harrington DP, Anderson JR, et al. A predictive model for aggressive non-Hodgkin's lymphoma. The International Non-Hodgkin's Lymphoma Prognostic Factors Project. N Engl J Med 1993;329:987-94

2 Solal-Celigny $\mathrm{P}$, Roy $\mathrm{P}$, Colombat $\mathrm{P}$, et al. Follicular lymphoma international prognostic index. Blood 2004;104:1258-65.

3 Sehn LH, Berry B, Chhanabhai M, et al. The revised International Prognostic Index (R-IPI) is a better predictor of outcome than the standard IPI for patients with diffuse large B-cell lymphoma treated with R-CHOP. Blood 2007;109:1857-61.

4 Illidge T, Tolan S. Current treatment approaches for diffuse large B-cell lymphoma. Leuk Lymphoma 2008;49:663-76.

5 Federico M, Bellei M, Marcheselli L, et al. Follicular lymphoma international prognostic index 2: a new prognostic index for follicular lymphoma developed by the international follicular lymphoma prognostic factor project. J Clin Oncol 2009;27:4555-62.

6 Freedman A. Follicular lymphoma: 2012 update on diagnosis and management. Am J Hematol 2012;87:988-95.

7 Chan WC, Armitage J0, Gascoyne R, et al. A clinical evaluation of the International Lymphoma Study Group classification of non-Hodgkin's lymphoma. Blood 1997:89:3909-18.

8 Canioni $D$, Brice $P$, Lepage $E$, et al. Bone marrow histological patterns can predict survival of patients with grade 1 or 2 follicular lymphoma: a study from the Groupe d'Etude des Lymphomes Folliculaires. Br J Haematol 2004;126:364-71.

9 Thiele J, Zirbes TK, Kvasnicka HM, et al. Focal lymphoid aggregates (nodules) in bone marrow biopsies: differentiation between benign hyperplasia and malignant lymphoma_a practical guideline. J Clin Pathol 1999;52:294-300.

10 Torlakovic E, Torlakovic G, Brunning RD. Follicular pattern of bone marrow involvement by follicular lymphoma. Am J Clin Pathol 2002;118:780-6.

11 Fend F, Kremer M. Diagnosis and classification of malignant lymphoma and related entities in the bone marrow trephine biopsy. Pathobiology 2007;74:133-43.

12 Navone R, Valpreda M, Pich A. Lymphoid nodules and nodular lymphoid hyperplasia in bone marrow biopsies. Acta Haematol 1985;74:19-22.

13 Zhang QY, Foucar K. Bone marrow involvement by Hodgkin and non-Hodgkin lymphomas. Hematol Oncol Clin North Am 2009;23:873-902.

14 van Dongen JJM, Langerak AW, Bruggemann $M$, et al. Design and standardization of PCR primers and protocols for detection of clonal immunoglobulin and T-cell receptor gene recombinations in suspect lymphoproliferations: Report of the BIOMED-2 Concerted Action BMH4-CT98-3936. Leukemia 2003;17:2257-317.

15 van Krieken J, Langerak AW, Macintyre EA, et al. Improved reliability of lymphoma diagnostics via PCR-based clonality testing:-Report of the BIOMED-2 concerted action BHM4-CT98-3936. Leukemia 2007;21:201-6.

16 Evans PAS, Pott C, Groenen P, et al. Significantly improved PCR-based clonality testing in B-cell malignancies by use of multiple immunoglobulin gene targets. Report of the BIOMED-2 Concerted Action BHM4-CT98-3936. Leukemia 2007;21:207-14.

17 Ilgenfritz RB, Kayasut K, Le Tourneau A, et al. Correlation between molecular and histopathological diagnoses of $B$ cell lymphomas in bone marrow biopsy and aspirates. J Clin Pathol 2009;62:357-60.

18 Talaulikar D, Shadbolt B, Dahlstrom JE, et al. Routine use of ancillary investigations in staging diffuse large B-cell lymphoma improves the International Prognostic Index (IPI). J Hematol Oncol 2009:22:49-57.

19 Arima H, Maruoka H, Nasu K, et al. Impact of occult bone marrow involvement on the outcome of rituximab plus cyclophosphamide, doxorubicin, vincristine and prednisone therapy for diffuse large B-cell lymphoma. Leuk Lymphoma 2013:54:2645-53.

20 Kang YH, Park CJ, Seo EJ, et al. Polymerase chain reaction-based diagnosis of bone marrow involvement in 170 cases of non-Hodgkin lymphoma. Cancer 2002;94:3073-82.
21 Mitterbauer-Hohendanner G, Mannhalter C, Winkler K, et al. Prognostic significance of molecular staging by PCR-amplification of immunoglobulin gene rearrangements in diffuse large B-cell lymphoma (DLBCL). Leukemia 2004;18:1102-7.

22 Swerdlow SH, Campo E, Harris NL, et al. eds. WHO classification of tumours of haematopoietic and lymphoid tissues. 4th edn. Lyon: IARC Press, 2008.

23 Berget $E$, Helgeland L, Molven A, et al. Detection of clonality in follicular lymphoma using formalin-fixed, paraffin-embedded tissue samples and BIOMED-2 immunoglobulin primers. J Clin Pathol 2011;64:37-41.

24 Coad JE, Olson DJ, Christensen DR, et al. Correlation of PCR-detected clonal gene rearrangements with bone marrow morphology in patients with $B$-lineage lymphomas. Am J Surg Pathol 1997;21:1047-56.

25 Crotty PL, Smith BR, Tallini G. Morphologic, immunophenotypic, and molecular evaluation of bone marrow involvement in non-Hodgkin's lymphoma. Diagn $\mathrm{Mol}$ Pathol 1998;7:90-5

26 Fodinger $\mathrm{M}$, Winkler $\mathrm{K}$, Mannhalter $\mathrm{C}$, et al. Combined polymerase chain reaction approach for clonality detection in lymphoid neoplasms. Diagn Mol Pathol 1999:8:80-91.

27 Krober SM, Horny HP, Greschniok A, et al. Reactive and neoplastic lymphocytes in human bone marrow: morphological, immunohistological, and molecular biological investigations on biopsy specimens. J Clin Pathol 1999;52:521-6

28 Brinckmann R, Kaufmann O, Reinartz B, et al. Specificity of PCR-based clonality analysis of immunoglobulin heavy chain gene rearrangements for the detection of bone marrow involvement by low-grade B-cell lymphomas. J Pathol 2000;190:55-60

29 Maes B, Achten R, Demunter A, et al. Evaluation of B cell lymphoid infiltrates in bone marrow biopsies by morphology, immunohistochemistry, and molecular analysis. J Clin Pathol 2000;53:835-40.

30 Braunschweig R, Baur AS, Delacretaz F, et al. Contribution of IgH-PCR to the evaluation of $B$-cell lymphoma involvement in paraffin-embedded bone marrow biopsy specimens. Am J Clin Pathol 2003;119:634-42.

31 Romaguera JE, McLaughlin P, North L, et al. Multivariate analysis of prognostic factors in stage IV follicular low-grade lymphoma: a risk model. J Clin Oncol 1991;9:762-9.

32 Dana BW, Dahlberg S, Nathwani BN, et al. Long term follow-up of patients with low-grade malignant lymphomas treated with doxorubicin-based chemotherapy or chemoimmunotherapy. J Clin Oncol 1993;11:644-51.

33 Schmid C, Isaacson PG. Bone marrow trephine biopsy in lymphoproliferative disease. J Clin Pathol 1992; 45:745-50.

34 Duggan PR, Easton D, Luider J, et al. Bone marrow staging of patients with non-Hodgkin lymphoma by flow cytometry-correlation with morphology. Cancer 2000:88:894-9.

35 Stacchini A, Demurtas A, Godio L, et al. Flow cytometry in the bone marrow staging of mature B-cell neoplasms. Cytom Part B-Clin Cytom 2003;54B: 10-8.

36 Perea $\mathrm{G}$, Altes $\mathrm{A}$, Bellido $\mathrm{M}$, et al. Clinical utility of bone marrow flow cytometry in B-cell non-Hodgkin lymphomas (B-NHL). Histopathology 2004;45: 268-74.

37 Schmidt B, Kremer M, Gotze K, et al. Bone marrow involvement in follicular lymphoma: comparison of histology and flow cytometry as staging procedures. Leuk Lymphoma 2006;47:1857-62.

38 lancu $D$, Hao S, Lin $\mathrm{P}$, et al. Follicular lymphoma in staging bone marrow specimens - correlation of histologic findings with the results of flow cytometry immunophenotypic analysis. Arch Pathol Lab Med 2007;131:282-7.

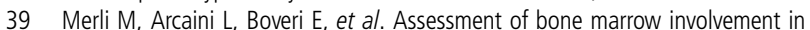
non-Hodgkin's lymphomas: comparison between histology and flow cytometry. Eur J Haematol 2010;85:405-15. 